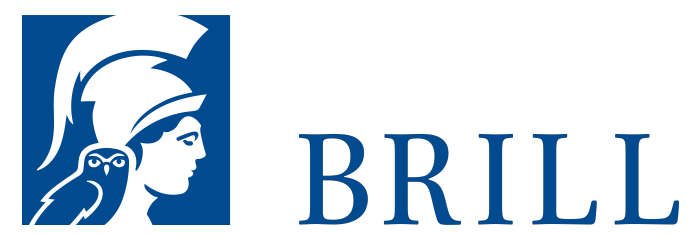

\title{
Von der Darstellungsmetaphysik zur Darstellungspragmatik
}

Eine historisch-systematische Untersuchung von Platon bis Davidson

Author: Tobias Schöttler

Darstellungen sind allgegenwärtig und spielen in den unterschiedlichsten Kontexten eine bedeutende Rolle, weshalb sie auch Gegenstand verschiedenster wissenschaftlicher Disziplinen sind. Jene Disziplinen beschränken sich jedoch auf bestimmte Darstellungsmedien oder -arten. Eine allgemeine Darstellungstheorie steht bislang noch aus. Das vorliegende Buch will dieses Desiderat mit einem historisch-systematischen Ansatz beheben. Die Adäquatheitsbedingungen für die anvisierte Theorie werden mittels der theoriegeschichtlichen Analyse gewonnen - von den Mimesistheorien der Antike über die Naturnachahmungstheorien der frühen Neuzeit bis zu den neueren Ansätzen in der Sprach-, Bild- und Wissenschaftssphilosophie. Das Gros jener Ansätze betreibt Metaphysik, insofern sie auf eine Letztbegründung der Drastellungspraxis aus sind. Die in diesem Buch entwickelte Darstellungspragmatik ersetzt das Begründungsprogramm durch ein systematisch anspruchsvolles Beschreibungsprogramm und ermöglich dadurch allererst eine Analyse der Pluralität von Darstellungspraxen und ihrer vielfältigen Funktionen. Damit liefert der pragmatische Ansatz den adäquaten Rahmen für eine allgemeine Darstellungstheorie.

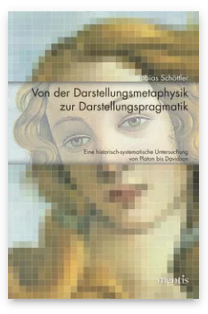

Pages: 360

Seiten

Language:

German

Subjects:

General,

Philosophy

Publisher: Brill | mentis

E-Book (PDF)

Released online:

o1 Aug 2012

ISBN: 978-3-

89785-953-1

List price

USD \$68.00

Paperback

Publication date:

o1 Aug 2012

ISBN: 978-3-

89785-778-о

List price

USD $\$ 68.00$ 
For more information see brill.com

Order information: Order online at brill.com +44330 333 0049 | customerservices@brill.com Submission information: brill.com/authors

Titles published by Brill | Fink, Brill | mentis or Brill | Schöningh: +49(o)715413279216| brill@brocom.de 